\title{
El carácter vinculante de la jurisprudencia constitucional en el derecho alemán ${ }^{1}$
}

\section{The binding nature of constitutional jurisprudence in german law}

\section{Jorge Ricardo Palomares García ${ }^{2}$}

Fecha de recepción: 2 de mayo de 2015

Fecha de aprobación: 7 de junio 2015

\section{RESUMEN}

La implementación del sistema de precedente en Colombia implica no solo la resolución de cuestiones materiales, tales como la identidad del modelo jurídico colombiano o la reconfiguración del sistema de fuentes, sino también de cuestiones metodológicas, tales como la determinación de las técnicas de identificación, interpretación y aplicación de reglas de precedente. Por ello, el presente artículo analiza cómo, en el ordenamiento alemán, se han construido unos criterios para la identificación del precedente, a fin de establecer cómo ellos pueden aportar a la construcción de una metodología de identificación de precedente en Colombia.

Palabras clave: Jurisprudencia constitucional, precedente, argumentos determinantes.

1 El presente artículo es resultado de la investigación titulada Análisis comparado para la construcción metodolígica del precedente jurisprudencial en Colombia, dirigido y financiado por el Institudo de Estudios del Ministerio Público -IEMP-, mediante contrato CD-045-2014

2 Abogado, Magíster en Derecho de la Universität Konstanz de Alemania. Candidato a Doctor de la Universität Konstanz de Alemania. Docente investigador del área de Derecho público, con énfasis en Derecho constitucional y jurisprudencia constitucional de la Univerisdad Libre, seccional Bogotá. Miembro del grupo de investigación Derecho constitucional nacional y comparado. Correo Electronico: jorge.palomares-garcia@hotmail.com 


\begin{abstract}
The implementation of the system of precedent in Colombia involves not only resolving material issues, such as the identity of the Colombian legal model or system reconfiguration of sources but also of methodological issues, such as determining identification techniques, interpretation and application of rules of precedent. Therefore, this article analyzes how, in the German system, have been built criteria for the identification of the above, in order to establish how they can contribute to building a methodology for identifying precedent in Colombia.
\end{abstract}

Keywords: Constitutional jurisprudence, precedent, decisive arguments. 


\section{INTRODUCCIÓN}

En virtud de losfenómenos en el sistema defuentes, propios del neoconstitucionalismo, el juez colombiano, especialmente el juez constitucional, ha asumido un papel determinante en la comprensión y aplicación de las fuentes del sistema jurídico colombiano. Las normas constitucionales, vinculantes a todos los poderes públicos -especialmente en torno a los derechos fundamentales-, logran su concreción mediante reglas y subreglas, diseñadas por el juez constitucional.

Sin embargo, debido a la redacción de la norma constitucional que consagra el sistema de fuentes en Colombia, el empleo de estas reglas y subreglas ha ocasionado dos cuestionamientos fundamentales, relacionados con la vinculatoriedad y el método. La primera cuestión, que pude considerarse como fundamental y permanente en el Derecho colombiano, consiste en el valor vinculante de las reglas y subreglas establecidas por los jueces; en otras palabras, el Derecho colombiano se pregunta si es posible sostener la existencia de un precedente. Dicha cuestión, que a inicios de la jurisprudencia Corte Constitucional de 1991 suscitó varios interrogantes y conflictos, se ha superado en cierta medida. Por una parte, la jurisprudencia constitucional construyó un discurso jurídico que sostiene el valor vinculante de las decisiones judiciales, como garantía de los principios de igualdad, seguridad jurídica y confianza legítima ${ }^{3}$. Por otra parte, y debido a los problemas de aceptación del carácter vinculante de las decisiones judiciales por parte de otras cortes y de los demás poderes públicos, el Legislador, a través de leyes tales como la 1395 de 2009, la 1437 de 2011 y la 1452 de 2012, ha consagrado que las decisiones judiciales, tanto de la Corte Constitucional como de la Corte Suprema de Justicia y el Consejo de Estado, son vinculantes no solo para los jueces, sino también para las demás autoridades del Estado.

De este carácter vinculante de las decisiones judiciales - precedente- surge la segunda inquietud y consiste, básicamente, en cómo determinar qué es lo vinculante de una decisión judicial, es decir, cuál de las partes de la decisión judicial, expuestas

3 Véase las sentencias de la Corte Constitucional C-083 de 1995, SU-047 de 1999, C-836 de 2001 y T-292 de 2006. 
por la Corte Constitucional, obligan a los jueces y las autoridades a un respeto y cumplimiento de las mismas. Esta cuestión implica la necesidad de una metodología de identificación de la regla del precedente, que le permita al operador jurídico disgregar una decisión judicial y poder tomar las reglas y subreglas establecidas en una sentencia, interpretarlas y aplicarlas al caso objeto de decisión. Esta inquietud no ha obtenido una respuesta contundente en el Derecho colombiano. Por una parte, la literatura jurídica colombiana ha centrado sus esfuerzos en resolver los problemas de jerarquización del precedente ante una posible contradicción con la normativa colombiana, especialmente con el art. 230 inc. $2^{\circ}$ de la Constitución Política de Colombia. Por otra parte, la Corte Constitucional no ha asumido una postura clara en torno a la metodología de identificación de precedente. En las primeras sentencias sobre el valor de las decisiones judiciales, especialmente de los máximos tribunales, la Corte Constitucional se enfocó en las cuestiones sobre el deber de protección de la intgridad y supremacía de la Constitución, a través de las interpretaciones de la Corte Constitucional (Corte Constitucional, SC 083 de 1995). Posteriormente, la Corte Constitucional trató de clarificar el elemento vinculante en la decisión judicial, a saber, la ratio decidendi (Corte Constitucional, SU 047 de 1999). Sin embargo, en jurisprudencia posterior la Corte Constitucional abrió la posibilidad de darle carácter vinculante a las obiter dicta (Corte Constitucional, SC 836 de 2001). La falta de claridad sobre la parte constitutiva de precedente ha impedido determinar qué es lo vinculante en una decisión judicial. Asimismo, en la sentencia T-292 de 2006, considerada por la literatura jurídica colombiana como aquella que reconoce el precedente y ofrece una metodología preliminar de identificación (Molinares, 2011 \& Lancheros, 2012), si bien la Corte Constitucional ofrece unos pasos para la identificación del precedente, esta decisión no contempla una metodología estructurada y no resuelve problemas en torno a la interpretación y aplicación de reglas y subreglas identificadas en la sentencia precedente.

Debido a la falta de profundidad de los estudios en torno a las cuestiones metodológicas del precedente se presentan ciertos inconvenientes en los poderes públicos al momento de aplicar un precedente. Ello se ve reflejado en algunas exhortaciones recientes de la Corte Constitucional, para que precedentes en distintos temas, como la salud, la pensión -entre otros-, sean respetados por las autoridades estatales, especialmente 
los jueces ${ }^{4}$. Igualmente, es necesario tener en cuenta que, en virtud de los procesos legislativos, las autoridades administrativas y los jueces, tanto de la jurisdicción ordinaria como contenciosa administrativa, deben, en virtud de especiales figuras, tomar decisiones conforme a criterios jurisprudenciales -sentencias de unificación de la Corte Suprema de Justicia y del Consejo de Estado-. Esta acción no será fácil, pues no existe un criterio metodológico para identificar una sentencia que se considere como precedente, disgregarla en sus elementos de forma clara, identificar las reglas y subreglas, así como poder interpretarlas.

Por ello, la presente investigación tiene como objeto construir un modelo metodológico de identificación, aplicación e interpretación de precedentes judiciales, que le facilite tanto al juez, como a las autoridades públicas, comprender el valor de las decisiones judiciales y la forma en que estas deben ser aplicadas en la actuación del Estado. Asimismo, esta investigación facilitaría a los particulares, especialmente a quienes ejercen la profesión jurídica (abogados, docentes universitarios e investigadores), determinar las decisiones judiciales significativas bien sea en el ejercicio del litigio, de la enseńanza de contenidos jurídicos disciplinares o de identificación de líneas jurisprudenciales.

Este Proyecto, a su vez, se divide en dos fases. La primera, objeto del presente documento, consiste en la determinación de las influencias foráneas en el razonamiento judicial colombiano, a fin de establecer cuáles pueden ser los elementos comunes, en términos metodológicos, que permitan la construcción de una metodología de identificación, interpretación y aplicación del precedente; en otras palabras, consiste en una fase de Derecho comparado, centrada en la identificación de las metodologías de precedente en países del área continental y del common law. La segunda fase, objeto de una propuesta posterior, consistiría en el diseño e implementación de un modelo metodológico que recoja los resultados de la primera fase de investigación.

Los ordenamientos jurídicos objeto de estudio del proyecto para el Instituto de Estudios del Ministerio Público (IEMP) son: Estados Unidos, Alemania, España,

4 Véase, por ejemplo, la exhortación de la Corte Constitucional a los jueces de la República, de dar estricto cumplimiento a los lineamientos en materia del régimen transición pensional, consagrados en precedentes tales como las sentencias C-789 de 2002, SU-062 de 2010, C-1024 de 2004, entre otros. 
Chile \& Colombia. Ahora bien, de responsabilidad personal, se liderará la investigación del Sistema alemán, chileno, colombiano y norteamericano.

\section{Metodología}

El estudio comparado de los efectos de las decisiones judiciales constitucionales parte de un consenso, aparentemente, universal en los ordenamientos jurídicos occidentales. Dicho elemento consiste en el valor de las constituciones que dieron paso a la teoría del neoconstitucionalismo.

Este valor, de acuerdo al amplio consenso de la literatura, consiste en considerar la constitución como una norma vinculante para el Estado, así como para sus autoridades. A su vez, esta norma goza de dos características especiales. La primera es ser una norma de rango jerárquico superior (Balaguer, 2000; Guastini, 2007; Rubio, 2000) que subordina las demás fuentes del Derecho estatal; la segunda es condicionar la existencia de las demás normas que componen el ordenamiento jurídico, así como la actuación de todas las autoridades del Estado (Carbonell, 2004; Guastini, 2007). Ello puede verse en la redacción de las normas constitucionales, en las cuales, existe una declaración del valor de la constitución. Por ejemplo:

\begin{tabular}{|cll} 
Alemania & $\begin{array}{l}\text { Art. } 1 \text { inc. } 3 \\
\text { GG }\end{array}$ & $\begin{array}{l}\text { Los siguientes Derechos fundamentales vinculan a los poderes } \\
\text { legislativo, ejecutivo y judicial como derecho directamente } \\
\text { aplicable }\end{array}$ \\
\hline Chile & $\begin{array}{l}\text { Art. } 6 \\
\text { inc. } 1 \text { y } 2 \\
\text { Constitución } \\
\text { chilena }\end{array}$ & $\begin{array}{l}\text { Los órganos del Estado deben someter su acción a la Constitución } \\
\text { y las normas dictadas conforme a ella. } \\
\text { Los preceptos de esta Constitución obligan tanto a los titulares o } \\
\text { integrantes de dichos órganos, como a toda persona, institución o } \\
\text { grupo }\end{array}$ \\
\hline España & $\begin{array}{l}\text { Art. } 4 \text { inc. } 1 \\
\text { Const. Pol }\end{array}$ & $\begin{array}{l}\text { La Constitución es norma de normas. En todo caso de } \\
\text { incompatibilidad entre la Constitución y la Ley u otra norma } \\
\text { jurídica, se aplicarán las disposiciones constitucionales. }\end{array}$ \\
& $\begin{array}{l}\text { Constitución } \\
\text { Los ciudadanos y los poderes públicos están sujetos a la } \\
\text { Constitución y al resto del ordenamiento jurídico. }\end{array}$ \\
\hline
\end{tabular}

Fuente: elaboración Propia 
En el caso norteamericano, el valor normativo de la Constitución es declarado por la jurisprudencia de la Corte Suprema Justicia de los Estados Unidos, especialmente, a través del caso Marbury v. Madison. En él, la Corte Suprema de Justicia de los Estados Unidos manifestó ${ }^{5}$ que:

It is emphatically the duty of the Judicial Department to say what the law is. Those who apply the rule to particular cases must, of necessity, expound and interpret the rule. If two laws conflict with each other, the Court must decide on the operation of each. If courts are to regard the Constitution, and the Constitution is superior to any ordinary act of the legislature, the Constitution, and not such ordinary act, must govern the case to which they both apply.

Un segundo aspecto consiste en la garantía de la constitución. En los ordenamientos jurídicos estudiados existe un consenso respecto a la necesidad de garantizar la integridad de las normas constitucionales. Dicha garantía se refleja, por una parte, en la necesidad de crear un órgano autónomo, con la función concreta de garantía de la Constitución. Esta garantía consiste, básicamente, en dos aspectos. Por una parte, debe buscarse que las normas constitucionales sean respetadas por los poderes públicos -bien sea a través de procedimientos de control constitucional abstracto o concreto-. Por otra parte, la garantía de la Constitución consiste en resolver las diferencias existentes entre la norma constitucional y una disposición jurídica inferior, a fin de garantizar la prevalencia de la norma constitucional.

Este órgano, a su vez, se ubicó en la rama judicial del poder público -salvo Chile y España, que cuentan con un apartado único para sus tribunales constitucionales- pero con unas características especiales. La primera de ellas consiste en que pese a contar con las características generales de los demás tribunales, los tribunales constitucionales cuentan con competencias taxativamente consagradas en las constituciones. Estas funciones pueden resumirse en el control de la constitucionalidad de las normas infraconstitucionales y la garantía de Derechos fundamentales.

5 Marbury v. Madison, 5 U.S. 137, 1 Cranch 137, 2 L. Ed. 60 (1803). 


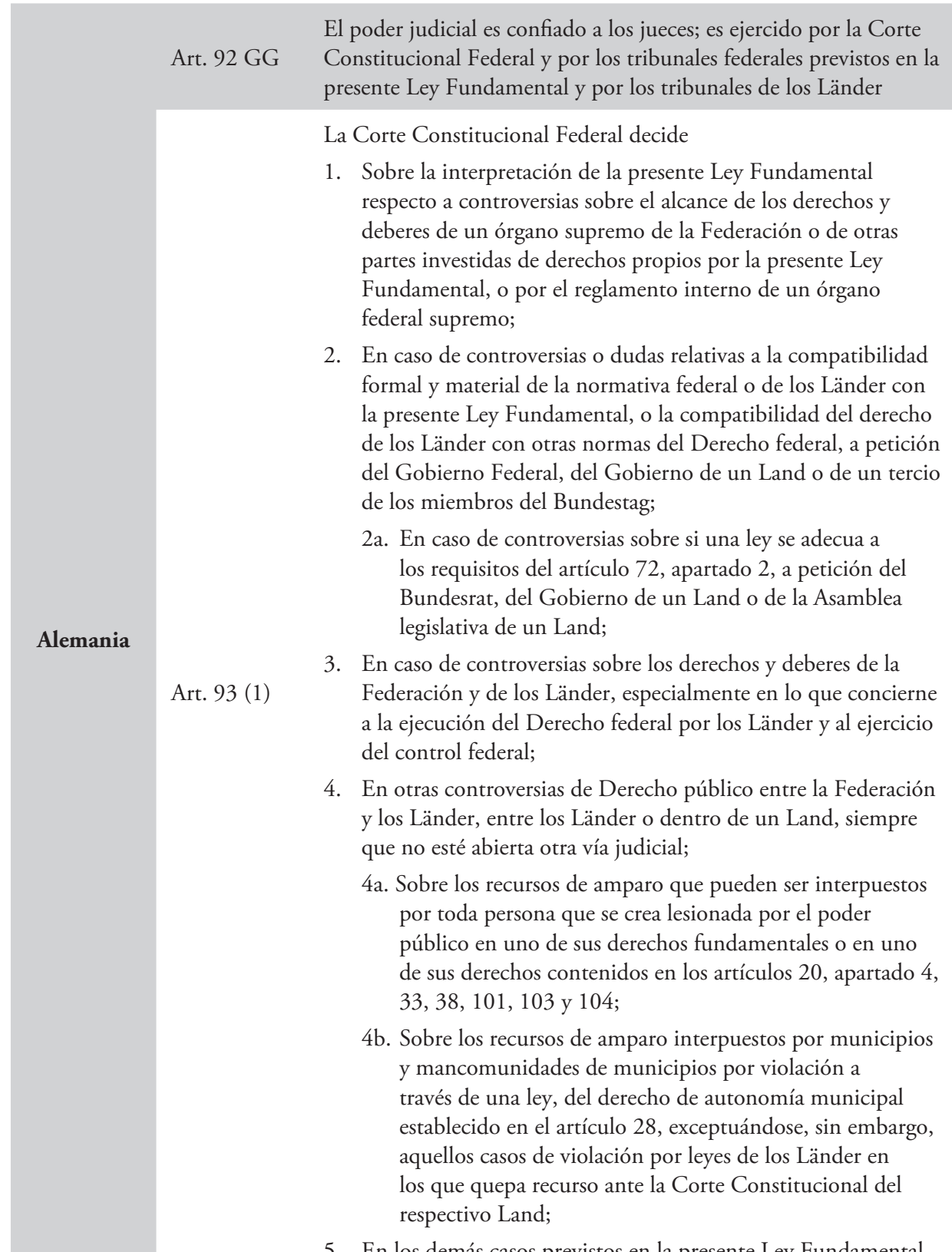


Son atribuciones del Tribunal Constitucional:

1. Ejercer el control de constitucionalidad de las leyes que interpreten algún precepto de la Constitución, de las leyes orgánicas constitucionales y de las normas de un tratado que versen sobre materias propias de estas últimas, antes de su promulgación;

2. Resolver sobre las cuestiones de constitucionalidad de los autos acordados dictados por la Corte Suprema, las Cortes de Apelaciones y el Tribunal Calificador de Elecciones;

3. Resolver las cuestiones sobre constitucionalidad que se susciten durante la tramitación de los proyectos de ley o de reforma constitucional y de los tratados sometidos a la aprobación del Congreso;

4. Resolver las cuestiones que se susciten sobre la constitucionalidad de un decreto con fuerza de ley;

5. Resolver las cuestiones que se susciten sobre constitucionalidad con relación a la convocatoria a un plebiscito, sin perjuicio de las atribuciones que correspondan al Tribunal Calificador de Elecciones;

6. Resolver, por la mayoría de sus miembros en ejercicio, la inaplicabilidad de un precepto legal cuya aplicación en

Chile cualquier gestión que se siga ante un tribunal ordinario o especial, resulte contraria a la Constitución;

7. Resolver por la mayoría de los cuatro quintos de sus integrantes en ejercicio, la inconstitucionalidad de un precepto legal declarado inaplicable en conformidad a lo dispuesto en el numeral anterior;

8. Resolver los reclamos en caso de que el Presidente de la República no promulgue una ley cuando deba hacerlo o promulgue un texto diverso del que constitucionalmente corresponda;

9. Resolver sobre la constitucionalidad de un decreto o resolución del Presidente de la República que la Contraloría General de la República haya representado por estimarlo inconstitucional, cuando sea requerido por el Presidente en conformidad al artículo 99;

10. Declarar la inconstitucionalidad de las organizaciones y de los movimientos o partidos políticos, como asimismo la responsabilidad de las personas que hubieran tenido participación en los hechos que motivaron la declaración de inconstitucionalidad, en conformidad a lo dispuesto en los párrafos sexto, séptimo y octavo del № $15^{\circ}$ del artículo 19 de 


\section{Chile}

esta Constitución. Sin embargo, si la persona afectada fuera el Presidente de la República o el Presidente electo, la referida declaración requerirá, además, el acuerdo del Senado adoptado por la mayoría de sus miembros en ejercicio;

11. Informar al Senado en los casos a que se refiere el artículo 53 número 7) de esta Constitución;

12. Resolver las contiendas de competencia que se susciten entre las autoridades políticas o administrativas y los tribunales de justicia, que no correspondan al Senado;

13. Resolver sobre las inhabilidades constitucionales o legales que afecten a una persona para ser designada Ministro de Estado, permanecer en dicho cargo o desempeñar simultáneamente otras funciones;

14. Pronunciarse sobre las inhabilidades, incompatibilidades y causales de cesación en el cargo de los parlamentarios;

15. Calificar la inhabilidad invocada por un parlamentario en los términos del inciso final del artículo 60 y pronunciarse sobre su renuncia al cargo, $y$

16. Resolver sobre la constitucionalidad de los decretos supremos, cualquiera sea el vicio invocado, incluyendo aquéllos que fueren dictados en el ejercicio de la potestad reglamentaria autónoma del Presidente de la República cuando se refieran a materias que pudieran estar reservadas a la ley por mandato del artículo 63.

Art. 116

Const. Pol
La Corte Constitucional, la Corte Suprema de Justicia, el Consejo de Estado, el Consejo Superior de la Judicatura, la Fiscalía General de la Nación, los Tribunales y los Jueces, administran Justicia. También lo hace la Justicia Penal Militar.

1. Decidir sobre las demandas de inconstitucionalidad que promuevan los ciudadanos contra los actos reformatorios de la Constitución, cualquiera que sea su origen, sólo por vicios de procedimiento en su formación.

2. Decidir, con anterioridad al pronunciamiento popular, sobre la constitucionalidad de la convocatoria a un referendo o a una Asamblea Constituyente para reformar la Constitución, sólo por vicios de procedimiento en su formación.

3. Decidir sobre la constitucionalidad de los referendos sobre leyes y de las consultas populares y plebiscitos del orden nacional. Estos últimos sólo por vicios de procedimiento en su convocatoria y realización. 


\section{Colombia Art. 241 \\ Const. Pol}

4. Decidir sobre las demandas de inconstitucionalidad que presenten los ciudadanos contra las leyes, tanto por su contenido material como por vicios de procedimiento en su formación.

5. Decidir sobre las demandas de inconstitucionalidad que presenten los ciudadanos contra los decretos con fuerza de ley dictados por el Gobierno con fundamento en los artículos 150 numeral 10 y 341 de la Constitución, por su contenido material o por vicios de procedimiento en su formación.

6. Decidir sobre las excusas de que trata el artículo 137 de la Constitución.

7. Decidir definitivamente sobre la constitucionalidad de los decretos legislativos que dicte el Gobierno con fundamento en los artículos 212, 213 y 215 de la Constitución.

8. Decidir definitivamente sobre la constitucionalidad de los proyectos de ley que hayan sido objetados por el Gobierno como inconstitucionales, y de los proyectos de leyes estatutarias, tanto por su contenido material como por vicios de procedimiento en su formación.

9. Revisar, en la forma que determine la ley, las decisiones judiciales relacionadas con la acción de tutela de los derechos constitucionales.

10. Decidir definitivamente sobre la exequibilidad de los tratados internacionales y de las leyes que los aprueben. Con tal fin, el Gobierno los remitirá a la Corte, dentro de los seis días siguientes a la sanción de la ley. Cualquier ciudadano podrá intervenir para defender o impugnar su constitucionalidad. Si la Corte los declara constitucionales, el Gobierno podrá efectuar el canje de notas; en caso contrario no serán ratificados. Cuando una o varias normas de un tratado multilateral sean declaradas inexequibles por la Corte Constitucional, el Presidente de la República sólo podrá manifestar el consentimiento formulando la correspondiente reserva.

11. Darse su propio reglamento.
Art. 9 inc. 1

España Constitución 1978
1. El Tribunal Constitucional tiene jurisdicción en todo el territorio español y es competente para conocer:

a. Del recurso de inconstitucionalidad contra leyes y disposiciones normativas con fuerza de ley. La declaración de inconstitucionalidad de una norma jurídica con rango 


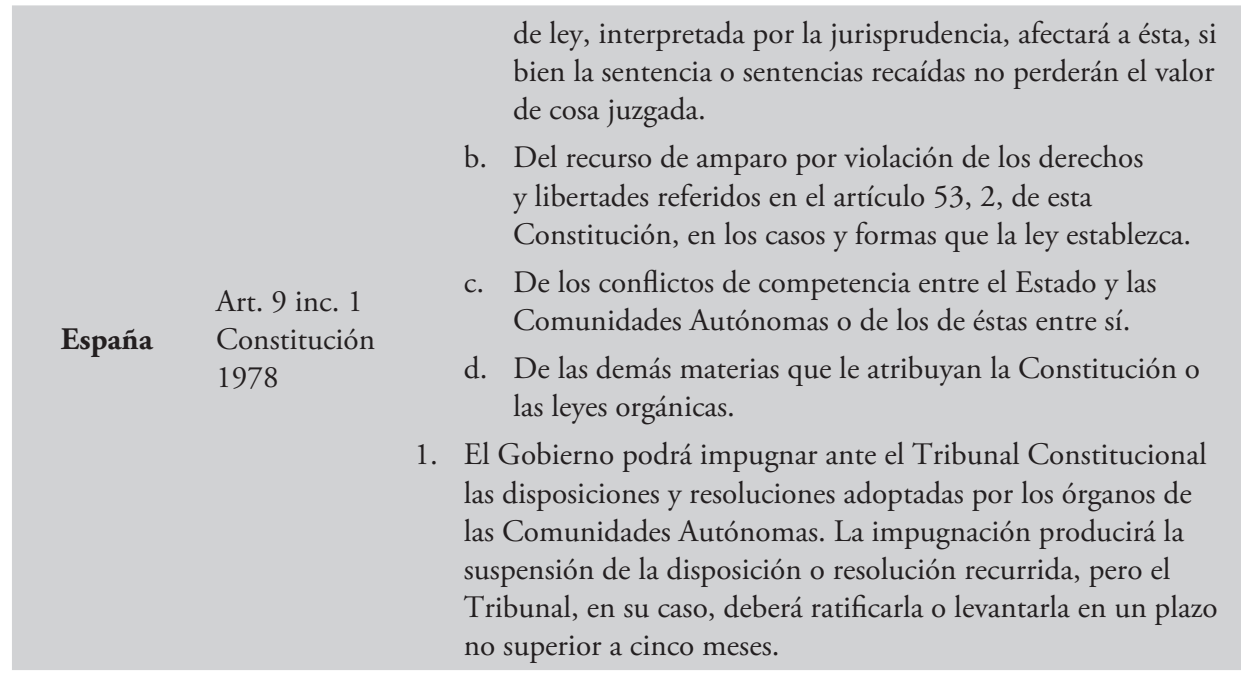

Fuente: elaboración Propia

En el caso norteamericano, no se reconoce, expresamente, una competencia exclusiva de revisión constitucional a favor de la Corte Suprema de Justicia de los Estados Unidos. Sin embargo, y como lo sostuvo este tribunal, esta competencia puede derivarse de la interpretación de la norma constitucional. El art. V sección 2 párrafo 1 de la Constitución de los Estados Unidos establece que el poder judicial encabezado por la Corte Suprema de Justicia de los Estados Unidos, conforme al art. V sección 1 párrafo único de la Constitución- está facultado para conocer de todos los casos en virtud de la Constitución, de las leyes, de los tratados [...]. La expresión todos los casos le permitió a la Corte Suprema de los Estados Unidos afirmar que ella cobija aquellos casos en los cuales existe un conflicto de naturaleza constitucional. En palabras de la Corte:

\section{The Supreme Court has the authority to review acts of Congress and determine whether they are unconstitutional and therefore void. ${ }^{6}$}

Sin embargo, debido a la ubicación de los garantes de la Constitución en la rama judicial, surge como cuestión el valor de sus decisiones. Ello se debe, por una

6 Marbury v. Madison, 5 U.S. 137, 1 Cranch 137, 2 L. Ed. 60 (1803). 
parte, a que los fallos de estos jueces constitucionales corresponden a la categoría: Jurisprudencia. Por otra parte, la jurisprudencia ha sido entendida en cada uno de los ordenamientos jurídicos como una fuente de Derecho secundaria a la Ley. Sin embargo, debido a la función especial de las cortes constitucionales, se abre la discusión de si puede hablarse de una jurisprudencia distinta, o de un precedente constitucional que goce fuerza vinculante sobre los demás poderes públicos. Ello ha abierto el debate, no nuevo pero sí actual, en torno a la configuración contemporánea de las fuentes del Derecho, así como el papel de los jueces constitucionales en ese sistema.

Por ello, el primer paso realizado durante el proceso de investigación consistió en determinar cómo se estructura el sistema de fuentes de cada uno de los países objeto de estudio, a partir tanto del enunciado normativo constitucional, como de las interpretaciones que los jueces y la literatura jurídica realizaron sobre dicho enunciado. Una vez determinada la configuración del sistema de fuentes, se estableció cómo se entendía la jurisprudencia constitucional y los efectos que las sentencias proferidas por los jueces constitucionales producían en el poder público. Ello permitió, en el caso concreto del Derecho alemán, identificar cómo éste, a partir de la interpretación del $\$ 31$ BVerfGG, logra crear un precedente sin desconocer las lógicas jurisdiccionales del juez constitucional alemán. Asimismo, permitió reconocer debates contemporáneos en los distintos ordenamientos, respecto a la alteración del valor de cada una de las fuentes, como la ley en el caso español (García-Berrio, 2006).

Cumplidos estos dos pasos, se procedió a determinar los criterios de fijación de precedente. Este paso permitió entender que, si bien puede argüirse un sistema precedencial creciente, las lógicas de identificación e implementación son distintas. Por ejemplo, algunos ordenamientos sostienen una estructura compuesta por obiter dictum y ratio decidendi (Zúñiga, 2006), mientras que otros, como el alemán, un sistema de argumentos determinantes o "Tragende Gründe".

En los siguientes apartados, se verá cada uno de los pasos, aplicados concretamente al Derecho alemán. 


\section{El sistema de fuentes en el Derecho alemán}

El ordenamiento jurídico alemán soporta actualmente su sistema de fuentes en la Ley fundamental para la República Federal de Alemania (en adelante GG, por su abreviación en alemán). Sin embargo, a diferencia de las demás constituciones, la GG establece una relación directa entre el principio de separación de poderes y las fuentes del Derecho. De acuerdo al art. 20 inc. 3 GG, el poder legislativo está sometido al orden constitucional; los poderes ejecutivo y judicial a la Ley y al Derecho.

Dicha norma, según la literatura, se entiende como la norma fundamental del sistema de fuentes alemán -Grundnorm der Rechtsquelle- (Rüthers; Fischer, 2010). Sin embargo, esta norma no enuncia taxativamente la expresión "decisión”. Por ello, es necesario determinar si, en el Derecho alemán, el precedente, como fuente, puede ubicarse en esta norma o, por el contrario, encuentra su sustento en otra disposición constitucional.

El primer consenso existente en la literatura jurídica consiste en la diferenciación entre "ley" y "Derecho" pues, si se argumenta que el "Derecho" se entiende como "ley", lo establecido en el Art. 20 Inc. 3 GG no sería más que una expresión tautológica. La cuestión se centró, en realidad, en qué debía entenderse por "ley", teniendo en cuenta que, en el Derecho alemán la misma puede entenderse desde dos ópticas. Una primera consistiría en definir la ley desde su aspecto formal, es decir, desde los órganos competentes para la expedición de la misma; mientras que la segunda, de tipo material, definiría la ley como toda disposición, de carácter general y abstracto, encargada de regular situaciones jurídicas, bien sea entre el Estado y el Particular, bien entre el Estado y sus órganos, o bien ente particulares. La literatura se ha inclinado por entender la ley desde un sentido material, pues sostener una dimensión formal podría excluir otras disposiciones estatales que cuentan con un carácter de aplicación general y abstracto, tales como Decretos, Reglamentaciones, y otros. Asimismo, y teniendo en cuenta el sistema federal alemán, la expresión "ley" debe entenderse, de acuerdo a la literatura jurídica alemana, no solo como aquella proferida a nivel federal -der Bund-, sino también a nivel federado - das Land-. 
En este sentido, la "ley", como fuente de Derecho del sistema jurídico alemán, debe entenderse como toda aquella disposición, de carácter general y abstracto, que regula situaciones jurídicas determinadas.

Si la ley, como toda aquella disposición general abstracta, incluye también actos administrativos de órganos federales y federados, es de cuestionarse qué se entiende por "Derecho". Para evitar caer en tautologías, el Derecho alemán buscó un elemento que lograse excluir la "ley" de éste término. Dicho elemento fue el "carácter escrito" de la ley, pues ella se expresa a través de Leyes, Códigos, Decretos, Reglamentos y Ordenanzas, que deben pasar por un procedimiento de elaboración y publicación, y finalmente se refleja en un escrito. Por tanto, la expresión "Derecho” deberá entenderse como toda aquella disposición no positivizada, pero con un valor vinculante. En este sentido, el Derecho alemán identificó dos fuentes jurídicas que cumplían con este requisito, a saber, la costumbre -Gewohnheitsrecht- y los Principios Generales de Derecho -allgemeine Rechtsgrundsätze-.

Por costumbre entiende la literatura alemana toda aquella práctica reiterada -allgemeine Übung - fundamentada en la convicción de que la misma tiene un valor jurídico -Überzeugung u opinio iuris- y que debe cumplir con tres requisitos concretos: a) concreción normativa -inhaltliche Bestimmtheit- o la capacidad de que la práctica sea formulada como regla; b) la vigencia, fundamentada en la permanencia de la práctica y de la convicción de valor jurídico y; c) la observancia-Observanz-. El valor jurídico de la costumbre en el sistema de fuentes del Derecho alemán está supeditado a la ley-untergeordnete Rolle-, es decir, su valor es inferior a la disposición escrita. Ello implica, por tanto, que la misma debe ser coherente con las disposiciones (y la constitución).

Los Principios Generales de Derecho se entienden no solo como el conjunto de principios, sino también de reglas que armonizan o "refinan" el ordenamiento jurídico. Dichos principios y reglas se encuentran en el desarrollo doctrinal y jurisprudencial (a través del ejercicio del Richterrecht). Ejemplo de ello es el principio de proporcionalidad. 


\section{La jurisprudencia constitucional en el sistema de fuentes alemán}

Del art. 20 inc. 3 GG surgió como una de las cuestiones fundamentales el papel de la jurisprudencia del Tribunal Federal Constitucional (en adelante BVerfG, por su abreviación en alemán).

Durante el proceso constituyente, existió la idea de consagrar al BVerfG como un órgano judicial de acuerdo a la tradición jurídica alemana (Roellecke, 2005, p. 1207). Por ello, fue consagrado en la GG como parte de poder judicial (Roellecke, 2005). Dicha consagración implica que el BVerfG cumple con las características comunes al poder judicial, es decir, "tiene una organización conforme a los demás tribunales, una actuación reservada al principio de justicia rogada o principio de acción -Antragsäbhängigkeit-, la obligación de toma de decisiones -Nachträglichkeit der Entscheidungen-a través de un proceso-Verfahren-y del ejercicio del deber de motivación -Begründungszwang-" (Roellecke, 2005, p. 1207). Sin embargo el BVerfG cuenta con unas características que lo distinguen del poder judicial tradicional y lo ubican en una especial posición.

La primera de ellas consiste en su vinculación respecto a las fuentes del Derecho. Mientras que, conforme al art. 20 inc. 3 GG el poder judicial está vinculado a la Ley y el Derecho, el BVerfG está obligado a emplear, como fuente directa, la constitución (Roellecke, 2005), debido a su función de garante de la misma -Hüter der Verfassung-. Ello se manifiesta en el control que puede ejercer el BVerfG sobre la conformidad de las normas -control normativo- (Roellecke, 2005) y acciones -control de amparo- infraconstitucionales con las disposiciones constitucionales.

Dicho control de conformidad constitucional implica, como segunda característica, que las decisiones del BVerfG se constituyen como una decisión última de poder (Roellecke, 2005). A través de los mecanismos constitucionales, especialmente del control de constitucionalidad de las leyes proferidas por el Parlamento alemán, el BVerfG puede realizar un control de las decisiones democráticas en virtud de la garantía de la supremacía jerárquica de la norma constitucional, como expresión de la voluntad original del pueblo alemán (Roellecke, 2005) -semejante al argumento esgrimido en el Derecho norteamericano en el caso Marbury v. Madison-. 
La tercera característica consiste en que, a diferencia de los demás tribunales federales, las competencias del BVerfG no son definidas por el legislador, sino directamente por el constituyente alemán (Roellecke, 2005).

La cuarta característica consiste en el tipo de argumentos empleados por el juez constitucional. A diferencia de los demás tribunales federales, el BVerfG, al tener como fuente primaria de aplicación la constitución, emplea argumentos basados en la figura de autolimitación judicial - richterlichen Selbstbeschränkungen- o, como lo sostiene Roellecke:

Das Bundesverfassungsgericht verwendet Argumente, die ein anderes Gericht nicht verwenden darf, etwa das Argument der richterlichen Selbstbeschränkung (“judicial self-restraint”) [...]. (2005, p. 1208)

De estas características, surge la cuestión de si la jurisprudencia constitucional alemana cumple una función semejante a la jurisprudencia de los demás tribunales de poder judicial, o si goza de algunos efectos especiales. La respuesta a este interrogante se ha discutido a la luz de la ley del BVerfG (en adelante BVerfGG, por su abreviación en alemán), que consagra, de acuerdo a la literatura, dos tipos de efectos de las decisiones del BVerfG. El primer tipo consiste en efectos procesales de la jurisprudencia constitucional (Kadenbach, 1955; Papier, 2006; Scheuner, 1954); mientras que el segundo tipo son los efectos normativos de las decisiones del BVerfG, los cuales son denominados por la literatura como efectos vinculantes -Bindungswirkungen- (Heusch, 2005; Kube, 2002; Lange, 1978; Maasen, 1975).

\section{A. Efectos procesales de las decisiones judiciales}

De acuerdo a la literatura y a la jurisprudencia constitucional alemana, las decisiones del BVerfGG tienen dos efectos procesales. El primero es la cosa juzgada -Rechtskraft- y la fuerza de ley -Gesetzeskraft-. El \$31 inc. 1 BVerfGG establece que las decisiones del BVerfG vinculan a los órganos constitucionales federales y de 
los estados federados, así como a todos los jueces y autoridades ${ }^{7}$; mientras que el $\$ 31$ inc. 2 BVerfGG consagra que las decisiones del BVerfG en determinados asuntos tienen fuerza de ley ${ }^{8}$.

Por fuerza de ley se entiende que la decisión del BVerfG goza del mismo efecto de aplicabilidad de las leyes. Sin embargo, dicho efecto no opera en todas las decisiones del BVerfG. De acuerdo al $\$ 31$ Inc. 2 en concordancia con el $\$ 13$ Nro. 6, 6a, 11, 12 y 14 , gozan de efecto de ley las decisiones judiciales que estén relacionadas con: a) las diferencias sobre la constitucionalidad formal o material de una ley; b) las diferencias en materia de legislación concurrente entre la Federación -Bund-y los estados federados -Länder-; c) la compatibilidad de leyes federales y federadas con la GG, así como la compatibilidad de las leyes federadas con las leyes federales; d) el valor del Derecho internacional en el ordenamiento alemán y; e) la vigencia de las normas federales como Derecho.

Las características de la fuerza de ley, que han logrado un consenso en la literatura, son tres. La primera consiste en el carácter general -Allgemeinverbindlichkeit(Seufert, 1979, p. 190) o de erga omnes de la parte resolutiva de una decisión del BVerfG -en alemán, die Entrscheidungsformel o Tenor (Klein, 1977, p. 698)-. Ello significa que las resoluciones tomadas por el BVerfG son de obligatorio cumplimiento para toda autoridad y persona. La segunda consiste en los efectos hacia el futuro de las decisiones del BVerfG. Si éste declara que una norma es inconstitucional, está se entenderá por nula hacia el futuro -nichtig ex tunc-(Kube, 2002, p. 737) y, por tanto, ni la autoridad ni el ciudadano pueden invocar nuevamente la norma inconstitucional (Lange, 1978; Sachs, 1979). La tercera característica es su publicidad. De acuerdo al $\$ 31$ inc. 2 BVerfGG, la parte resolutiva de la decisión del BVerfG debe, a través del Ministerio federal de justicia -Bundesministerium der Justiz-, publicar el diario oficial federal-Bundesgesetzbaltt- (Heusch, 2005, p. 527).

$7 \$ 31$ Abs. 1 BVerfGG. Die Entscheidungen des Bundesverfassungsgerichts binden die Verfassungsorgane des Bundes und der Länder sowie alle Gerichte und Behörden.

$8 \$ 31$ Abs. 2 BVerfGG. In den Fällen des $\$ 13$ Nr. 6, 6a, 11, 12 und 14, hat die Entscheidungen des Bundesverfassungsgerichts Gesetzeskraft. 
La segunda figura es la cosa juzgada -Rechtskraft-. Por ella se entiende, conforme a la literatura, una institución jurídica procesal relacionada con los efectos formales y materiales de la decisión del BVerfG (Heusch, 2005; Lange, 1978). Por cosa juzgada, en sentido formal, se entiende la imposibilidad de interponer recursos sobre una discusión judicial ya cerrada -Unanfechtbarkeit- (Heusch, 2005; Lange, 1978; Maasen, 1975); mientras que la cosa juzgada, en sentido material, está compuesta por varios aspectos: a) el subjetivo; b) el objetivo y; c) el temporal.

El aspecto subjetivo de la cosa juzgada material consiste en los efectos producidos sobre las partes procesales de la decisión judicial -Verfahrensbeteiligten- (Lange, 1978). Las partes involucradas en un fallo del BVerfG no podrán invocar, ante el mismo BVerfG o ante otra autoridad judicial, el mismo problema jurídico nuevamente (Klein, 1977; Maasen, 1975) -efecto inter partes (Heusch, 2005)-. Dicha prohibición no aplica, sin embargo, a aquellas personas que sean consideradas como terceros ajenos al proceso (Lange, 1978). Sin embargo, parte de la literatura manifiesta que dicho aspecto, en materia de la jurisprudencia constitucional, no opera en aquellos asuntos donde la controversia sea el control de constitucionalidad de una norma (Heusch, 2005). Ello se debe a que, en control de constitucionalidad, no existe como tal una parte procesal (Heusch, 2005).

El segundo aspecto es el objetivo. Consiste en la prohibición de discutir nuevamente sobre un asunto -konkreter Verfahrensgegenstand-ya decidido (Klein, 1997). De esta definición se derivan en el Derecho constitucional varios interrogantes. Entre ellos, es de resaltar uno relacionado directamente con el término objeto de discusión. Dicho interrogante consiste en determinar cuál apartado de la decisión judicial crea los efectos de la cosa juzgada. Para la parte mayoritaria de la literatura, los efectos de cosa juzgada material los produce la parte resolutiva de la decisión -Entscheidungsformel(Heusch, 2005; Lange, 1978; Maasen, 1975). Dicha afirmación se argumenta en la función de la parte resolutiva, pues en ella existe una orden concreta de cierre.

Para la parte minoritaria de la literatura, debe pensarse, sin embargo, en algunas variables. La primera variable consiste en la claridad de la orden. La parte minoritaria sostiene que la parte resolutiva, en ocasiones, no es clara por sí misma y, por ello, se hace necesario incluir dentro del efecto de cosa juzgada material, desde su aspecto 
objetivo, la parte motiva de la decisión -Entscheidungsgründe- (Maassen, 1975). Asimismo, en aquellos casos en los cuales el BVerfG declare la constitucionalidad de la norma sujeta a una determinada interpretación, el ejercicio interpretativo se encontrará no en la parte resolutiva, sino en la motivación de la sentencia. Sin embargo, la parte mayoritaria sostiene que, en realidad, dicho problema no existe. Si bien las ordenes pueden tener ciertos elementos que requieren de alguna aclaración, la parte motiva de la decisión constituye una herramienta interpretativa de la parte resolutiva, mas no un mandato expreso (Heusch, 2005 \& Maassen, 1975).

La segunda variable que considera la parte minoritaria, y a través de la cual se ha abierto espacio la posibilidad de un precedente vinculante (Kischel, 2006), consiste en la existencia de cosa juzgada en materia de expedición normativa a cargo del Legislativo. De acuerdo a la doctrina alemana, el \$31 Inc. 1 BVerfGG establece que las decisiones del BVerfG vinculan a todos los órganos constitucionales federales, sin distinción alguna. Ello implica que las decisiones del BVerfG son obligatorias para el Legislador.

De esta obligación surge el interrogante de si es posible que una decisión del BVerfG obligue al Legislador a no expedir nuevamente una norma anteriormente declarada inconstitucional. Este tema se conoce como la teoría de prohibición de reiteración -Widerholungsverbot- (Detterbeck, 1996; Kischel, 2006) y consiste en la posible existencia de una restricción al Legislador en su margen de configuración legislativa, pues, a futuro, aquel no podría expedir una nueva norma que contenga la misma contradicción declarada por el BVerfG en la decisión (Detterbeck, 1996).

La justificación de esta teoría radica en varios aspectos, entre ello: a) la función de interpretación auténtica de la constitución a cargo del BVerfG (Kischel, 2006) y; b) la función de colaboración entre el Legislador y el BVerfG para la configuración del orden constitucional (Kube, 2002).

Sin embargo, esta teoría ofrece, al menos, dos interrogantes. El primero de ellos consiste en cómo determinar una restricción por parte del BVerfG cuando en su decisión se opta por una constitucionalidad sujeta a una determinada interpretación, o se opta por una inconstitucionalidad parcial. Por otra parte, se 
cuestiona el ámbito de aplicación de la declaratoria de inconstitucionalidad a través de la norma paralela -Paralellnormen- (Detterbeck, 1996; Kube, 2002). Dicho problema consiste en determinar una constelación normativa -Normkonstellation(Kischel, 2006) donde sean aplicables, de forma casi idéntica, la declaratoria de constitucionalidad, constitucionalidad sujeta a interpretación, inconstitucionalidad o inconstitucionalidad parcial.

\section{B. El carácter vinculante-sentido material-de las decisiones del BVerfG}

Junto con los efectos procesales de las decisiones del BVerfG-del cual, a través de la cosa juzgada material podría extraerse parte de la justificación de sentencias vinculantes-, la literatura ha reconocido también un carácter especial de vinculatoriedad.

Su soporte normativo se encuentra, al igual que la cosa juzgada, en el \$31 Inc. 1 BVerfGG. Sin embargo, se diferencia de la cosa juzgada, pues mientras ésta es una figura procesal, la vinculatoriedad - Bindungswirkung - constituye una cuestión de las relaciones de poder entre las ramas del poder público (Heusch, 2005). Asimismo, existe una diferencia entre estas dos instituciones en la medida en que éstas tienen un círculo de destinatarios -Bindungsadressaten- distinto (Heusch, 2005).

Por otra parte, a diferencia de la cosa juzgada y de la fuerza de ley, la justificación del carácter vinculante de las decisiones del BVerfG reposan en los siguientes argumentos: a) el aseguramiento de la fuerza de dirección de la constitución (Heusch, 2005, p. 515) -die Sicherung der Direktionskraft der Verfassung-; b) la garantía de interpretación uniforme de la constitución (Heusch, 2005, p. 515) -einheitliche Auslegung der Verfassung zu garantieren- y; c) la orientación de la conducta de las autoridades públicas (Heusch, 2005, p. 520).

Por carácter vinculante se entiende, que todas las decisiones del BVerfG, sin importar si son emitidas en sala plena o solo por una sala -o Senat-, vinculan a todos los poderes públicos (Heusch, 2005) -ello implica una diferencia entre este efecto y la fuerza de ley, la cual está restringida a solo unos asuntos determinados-. Dicha definición implica un análisis desde dos dimensiones: a) la objetiva y; b) la subjetiva. 
Desde la dimensión objetiva, la literatura ha discutido, de forma similar a la discusión de cosa juzgada, si los efectos vinculantes son determinados solo por su Entscheidungsformel o también la parte motiva (Heusch, 2005). Sin embargo, a diferencia de la cosa juzgada, la literatura ha logrado un consenso al afirmar, que los efectos vinculantes de la decisión judicial se extienden no solo a la parte resolutiva, sino también a la parte motiva (Heusch, 2005). La cuestión consiste en cuál de los apartados de la parte motiva producen efectos vinculantes.

La literatura parte, para resolver esta cuestión, de un supuesto esencial. Las decisiones judiciales, especialmente las constitucionales, se leen en clave distinta al Derecho norteamericano. Ello significa, que para la literatura alemana no existen distinciones entre obiter dictum y ratio decidendi, sino la existencia de los argumentos determinantes de la decisión -tragenede Gründe-. Por ellos se entiende el conjunto de reglas jurídicas o enunciados normativos -Rechtssätzen- que el juez constitucional consagra en su decisión judicial. Estas reglas jurídicas, sin embargo, provienen no de un ejercicio arbitrario del BVerfG, sino de una legitimidad democrática, al estar dichas reglas jurídicas a la reserva constitucional y legal (Heusch, 2005).

Del concepto de argumentos determinantes de la decisión surge, sin embargo, la cuestión de cómo determinar aquellos al interior de la decisión judicial. Para ello, la literatura ha desarrollado dos criterios. El primero de ellos consiste en las interpretaciones de especialidad (Heusch, 2005). Al BVerfG le corresponde la interpretación de la constitución, más no la interpretación de normas correspondientes a otras áreas. En este sentido, la interpretación que hace el BVerfG permite conocer los contenidos y alcances de las normas constitucionales para, a partir de ellos, determinar si una norma infraconstitucional es constitucional o no. Sin embargo, los alcances ulteriores que pueda tener la norma objeto de constitucionalidad no corresponden al BVerfG, sino al juez especializado en el área -Fachgericht- (Heusch, 2005).

El segundo criterio es la determinación objetiva de los argumentos determinantes. Esto consiste en el ejercicio de establecer si el argumento puede ser omitido del razonamiento judicial sin que afecte el resultado final de la decisión. De acuerdo a Heusch 


\begin{abstract}
Danach sind tragend für die Entscheidung jene Rechtsätze, die nicht hinweggedacht werden können, ohne dass das konkrete Entscheidungsergebnis nach dem in der Entscheidung zum Ausdruck gekommen Gedankengang entfiele. (2005, p. 516)
\end{abstract}

En este sentido quedarían excluidos del concepto de argumentos determinantes de la decisión, todos aquellas reflexiones jurídicas que se ubican fuera de la relación entre la regla jurídica general y la decisión concreta (Heusch, 2005, p. 516).

Desde la dimensión subjetiva se encuentran vinculados, tanto a la decisión concreta como los argumentos determinantes de la misma, todos los órganos constitucionales, bien sean federales o de los estados federados (Heusch, 2005). Por órganos constitucionales se entiende todo sujeto jurídico cuyas competencias están reconocidas directa o indirectamente por la GG (Heusch, 2005). Asimismo, se entienden por obligados a todas aquellas partes con capacidad procesal (Heusch, 2005). Se enunciará en el punto IV la vinculación de los jueces a las decisiones del BVerfG.

\title{
IV. Dimensión vertical y horizontal de los efectos vinculantes de las decisiones del BVerfG
}

Dentro de la dimensión subjetiva del efecto vinculante de las decisiones del BVerfG se encuentran también los jueces. Sin embargo, debido a que el BVerfG se encuentra -como se enunció en el punto I- dentro del poder judicial, sus relaciones se establecen en dimensiones de verticalidad y horizontalidad.

Desde el carácter vertical, deben analizarse varios aspectos. Por un lado, la existencia de una relación pura entre jueces y el BVerfG y, por otro lado, la relación, en virtud de la organización federal, entre los tribunales federados y el BVerfG. En la primera variante, todos los jueces están obligados a respetar las decisiones del BVerfG. Ello significa, que tanto los jueces especializados como los jueces en ejercicio de protección constitucional de derechos deberán respetar los criterios -reglas jurídicasestablecidas por el BVerfG, así como la interpretación que haya hecho éste de la constitución (Heusch, 2005). En cuanto a la relación entre el BVerfG y los tribunales federados, éstos están vinculados a las interpretaciones realizadas por el BVerfG de 
la constitución, mas no de las interpretaciones que deban hacerse de cada una de las constituciones federadas (Heusch, 2005).

Con respecto al carácter horizontal, se deben diferenciar también dos escenarios. El primero consiste en el BVerfG en sala plena. En este escenario, se sostiene que el BVerfG no está sujeto al carácter vinculante (Heusch, 2005, p. 519). Ello significa, que el BVerfG puede variar su jurisprudencia. La razón de esta exclusión del carácter vinculante se encuentra en la función de actualización de los contenidos normativos constitucionales, es decir, el BverfG tiene la función de actualizar la interpretación y la aplicación de la constitución a nuevos desarrollos (Heusch, 2005, p. 519). Sin embargo, ello no significa que la jurisprudencia pueda variar abrupta o arbitrariamente. Por un lado existe el límite de autoridad, es decir, que si existen variaciones constantes podría ponerse en duda la posición y función del BVerfG; por otro lado existe el límite de confianza, es decir, que las decisiones del BVerfG deben garantizar la confianza ciudadana en la constitución y su aplicación (Heusch, 2005).

El segundo escenario consiste en la relación del BVerfG y sus respectivos senados -Senate- o cámaras-Kammer-. El BVerfG está compuesto por dieciséis magistrados, los cuales son divididos en dos senados, según el $\$ 2$ inc. 1 BVerfGG. Cada uno de estos senados puede, a su vez, estar compuesto por cámaras de tres magistrados, conforme el $\$ 15$ a inc. 1 BVerGG. Asimismo, la BVerfGG asigna competencias específicas a cada uno de los senados $-\mathrm{y}$, por tanto, a las cámaras que lo integranEn este escenario, una cámara no podrá variar la jurisprudencia libremente, que bien haya sido emitida por el BVerfG en pleno o por otra cámara. Para ello, deberá convocar al BVerfG en pleno (Heusch, 2005). 


\section{Conclusiones}

El Derecho constitucional alemán, a semejanza de los ordenamientos, especialmente el colombiano, ha construido una lógica de vinculatoriedad de las decisiones judiciales proferidas por el juez constitucional.

Dicha lógica derivó, básicamente, de dos aspectos concretos. El primero de ellos es la interpretación del art. 20 inc. 3 GG, que consagra un sistema de fuentes ligado estrechamente a la tridivisión de poderes. El segundo es la interpretación lograda del $\$ 31$ BVerfG. Si bien esta norma consagró los efectos procesales y de ley de las decisiones del BVerfG, ella permitió la inclusión del efecto vinculante y, por tanto, del precedente.

Sin embargo, este precedente se diferencia, al menos del precedente colombiano, en cuanto a su estructura. El sistema de precedente alemán se caracteriza por centrarse en un elemento, a saber, el argumento determinante. Este elemento, a su vez, se determina no a través de una estructuración compleja de la sentencia, sino de la identificación de tres elementos: a) el caso a resolver; b) el enunciado normativo y; c) la relación entre el enunciado normativo y el caso.

Lacuestión que surge, para la segunda fase, consiste en cómo estas lógicas de precedente alemán, así como la forma de identificación del argumento determinante, pueden servir para la construcción de una metodología aplicada al Derecho colombiano. Ello implicaría, en principio, un ejercicio de comparación desde la semejanza, es decir, desde aquellos componentes comunes entre el ordenamiento alemán y el colombiano. Estos elementos podrán identificarse, no a partir de las sentencias que dan identidad al sistema de fuentes colombiano, sino a partir del fallo que ha establecido, inicialmente, las reglas básicas de identificación del precedente. En otras palabras, será necesario establecer cómo la sentencia de tutela T-292 de 2006 puede tener elementos comunes con las lógicas del sistema de precedente alemán. 


\section{REFERENCIAS}

Balaguer, F. (2000). Constitución y ordenamiento jurídico. En AAVV, Teoría de la Constitución: Ensayos escogidos, pp. 177ss. México: UNAM, Ed. Porrúa.

Carbonell, M. (2004). Elementos de Derecho constitucional. México: UNAM, Ed. Fontamara.

Corte Constitucional (1995), sentencia de constitucionalidad C-083 de 1995, Pablo Antonio Bustos Sánchez v. Congreso de la República-art. 8 Ley 153 de 1887-.

Corte Constitucional (1999), sentencia de unificación SU-047 de 1999, Viviane Morales Hoyos v. Corte Suprema de Justicia-Sala de Casación penal.

Corte Constitucional (2001), sentencia de constitucionalidad C-836 de 2001, Carlos Alberto Maya Restrepo v. Congreso de la República-art. 4 Ley 169 de 1896-.

Corte Constitucional (2006), sentencia de constitucionalidad T-292 de 2006, Lucia Gómez Arias v. Compañia Flota Mercante en liquidación.

Detterbeck, S. (1996). Gelten die Entscheidungen des Bundesverfassungsgerichts auch in Bayern? En Neue juristische Wochenschrift (NJW), pp. 427ss. No. 49. Alemania.

García-Berrio, T. (2006). La controversia sobre el precedente judicial: un clásico del Derecho en constante renovación, pp. 127-152. En Foro, nueva época, No. 4.

Garrido , M. (2011). El valor de los precedentes judiciales en materia de igualdad. España: Universidad Alcalá.

Guastini, R. (2007). Estudios de teoría constitucional. México: UNAM, Ed. Fontamara.

Heusch, A. (2005). \$31 BVerfGG: Verbindlichkeit der Entscheidungen. En AAVV, Bundesverfassungsgerichtsgesetz: Mitarbeiterkommentar und Handbuch. Alemania. 
Kadenbach, E. (1955). Zur bindenen Wirkung der Entscheidungen des Bundesverfassungsgerichts. En Archiv des öffentlichen Rechts (AöR), No. 80, pp. 25ss.

Kischel, U. (2006). Darf der Gesetzgeber das Bundesverfassungsgericht ignorieren? Zum erneuten Erlass für nichtig erklärter Gesetze. En Archiv des öffentlichen Rechts, No. 131, pp. 227ss. Alemania

Klein, H. (1977). Probleme der Bindung des "einfaches Richters" an Entscheidungen des BVerfG. En Neue juristische Wochenschrift (NJW). No. 30, pp. 697ss. Alemania.

Kube, H. (2002). Die Bindungswirkung der Normverwerfung, en Die öffentliche Verwaltung (DöV). No. 55, pp. 737ss. Alemania.

Lancheros, J. (2012). El precedente judicial en Colombia y su estructura argumentativa. En Revista Dikaion, año 26, No. 21, Vol. 1, Universidad de la Sabana, 159-186.

Lange, K. (1978). Rechtskraft, Bindungswirkung und Gesetzkraft der Entscheidungen des Bundesverfassungsgerichts. En Juristische Schulung (JuS), pp. 1ss. Alemania.

Maasen, H. (1975). Probleme der Selbstbindung des Bundesverfassungsgerichts. En Neue juristische Wochenschrift (NJW), No. 28, pp. 1343ss. Alemania.

Molinares, V. (2011). El precedente constitucional: análisis de la sentencia T-292 de 2006 En Revista de Derecho, No. 35, pp. 118-144. Universidad del Norte.

Papier, H. (2006). Rechtsfolgen von Normenkontrollen, en Europäische Grundrechte Zeitschrift (EuGRZ), No. 33, pp. 530ss. Alemania.

Roellecke, G. (2005). Aufgaben und Stellung des Bundesverfassungsgerichts im Verfassungsgefüge. En AAVV, Handbuch des Staatsrechts der Bundesrepublik Deutschland, Band 3: Demokratie-Bundesorgane. Alemania.

Rubio, F. (2000). La constitución como fuente de Derecho. En AAVV, Teoría de la Constitución: ensayos escogidos. pp. 155ss. México: UNAM, Ed. Porrúa. 
Rüthers, B. y Fischer, C. (2010). Rechtstheorie, 5. Auflage. Alemania: C. H. Beck.

Sachs, M. (1979). Bindungswirkungen bei verfassungskonformer Gesetzauslegung durch das Bundesverfassungsgericht. En Neue juristische Wochenschrift (NJW), No. 32, pp. 334ss. Alemania.

Scheuner, U. (1954). Das Bundesverfassungsgericht und die Bindungskraft seiner Entscheidungen. En Die öffentliche Verwaltung, No. 7, pp. 641ss. Alemania.

Seuffert, W. (1979). Über Gesetzgebung, Rechtsprechung und Bindungswirkungen. En Archiv des öffentlichen Rechts (AöR), No. 104, pp. 176ss. Alemania.

Zúñiga, F. (2006). Sentencias del Tribunal constitucional y el poder judicial. El valor del precedente. En Estudios constitucionales, año 4, No. 1, pp. 151-172. 